\title{
THE EFFECT OF TEMPERATURE-DEPENDENT VISCOSITY AND THERMAL CONDUCTIVITY ON MICROPOLAR FLUID OVER A STRETCHING SHEET
}

\author{
Reza Keimanesh, Cyrus Aghanajafi
}

Original scientific paper

In this paper, the flow and heat transfer characteristics of a micropolar fluid flow over a stretching sheet are studied. The effects of magnetic field, radiation heat flux and porous sheet are investigated, and the viscosity and thermal conductivity are supposed temperature-dependent. The governing equations are formulated by boundary layer approximation and the theory of micropolar fluids. To solve the problem, the partial differential equations are transformed into the ordinary differential equations by using similarity solutions, and the achieved equations are solved by shooting method and fourthorder Runge-Kutta. The results show that the effects of magnetic field and porousness result in decrease of the velocity values in the boundary layers, but the presence of radiation heat flux results in the growth of the boundary layer thickness. Furthermore, the thickness of thermal boundary layer declines by increase of suction parameter and reduction of radiation and magnetic field effects.

Keywords: magnetic field; micropolar fluid; porous sheet; radiation; stretching sheet; thermal conductivity; viscosity

\section{Djelovanje o temperaturi ovisnog viskoziteta i toplinske vodljivosti na mikropolarni fluid preko elastičnog lima}

Izvorni znanstveni članak U radu se istražuju karakteristike protoka i prijenosa topline mikropolarnog toka fluida preko elastičnog lima. Istražuju se utjecaji magnetskog polja, toka topline radijacije i poroznog lima, uz pretpostavku da su viskoznost i toplinska vodljivost ovisne o temperature. Primijenjene su jednadžbe formulirane aproksimacijom graničnog sloja i teorijom mikropolarnih fluida. Za rješenje problema, parcijalne diferencijalne jednadžbe transformirane su u obične diferencijalne jednadžbe primjenom rješenja sličnosti, a dobivene jednadžbe rješavane su metodom izbacivanja i metodom Runge-Kutta četvrtog reda (fourth-order Runge-Kutta). Rezultati pokazuju da djelovanje magnetskog polja i poroznosti rezultira smanjenjem vrijednosti brzine u graničnim slojevima, strujanje topline radijacije rezultira povećanjem debljine graničnog sloja. Nadalje, debljina toplinskog graničnog sloja smanjuje se porastom usisnog parametra i redukcijom učinaka radijacijskog i magnetskog polja.

Ključne riječi: elastični lim; magnetsko polje; mikropolarni fluid; porozni lim; radijacija; toplinska vodljivost; viskoznost

\section{Introduction}

In the last few decades, many industrial processes, such as extrusion, glass-fiber and cooling the sheets, necessitate the research on heat transfer and boundary layer flow over a moving continuous sheet. On the other hand, a lot of fluids cannot be formulated as a Newtonian fluid, such as micropolar fluids which have microrotation as the extra degrees of freedom. Eringen [1] presented the theory of micropolar fluid to model these fluids. This theory can describe the flows with polar properties, for example the flows of liquid crystals, ferro-fluids, the colloidal fluid flows, bubbly liquids, the blood of animals, etc.

Prasad et al. [2] described a magnetohydrodynamic (MHD) viscoelastic fluid flow over a stretching sheet with variable viscosity. They solved the problem by similarity transformations, shooting method and fourth-order Runge-Kutta, and concluded that heat-sink parameter decreases the values of temperature profile in the boundary layer, but heat-source parameter increases it. In another research, Prasad et al. [3] studied the effects of temperature-dependent fluid properties in the presence of magnetic field, and concluded that the augmentation of variable viscosity parameter and variable thermal conductivity parameter leads to the increase of temperature values in thermal boundary layer. Chiam [4] considered a variable thermal conductivity flow in a stagnation-point flow and understood that the increment of variable thermal conductivity results in the growth of thermal boundary layer thickness while wall temperature could be constant or variable. Odda and Farhan [5] studied the effects of variable properties of micropolar fluid on heat transfer from a stretching sheet by Chebyshev finite difference method and showed that the suction effect leads to decrease of temperature values in the boundary layer, while blowing has an inverse influence. Mahmoud [6] investigated the effects of thermal radiation and MHD on micropolar fluid flow over a stretching sheet, and the results showed that the increase of magnetic parameter or thermal conductivity parameter thickens thermal boundary layer. Rahman et al. [7] considered the effects of variable surface temperature on heat transfer to a micropolar fluid along a stretching sheet while the viscosity is assumed temperature-dependent. They showed that variable wall temperature leads to the lower values of temperature in thermal boundary layer than the uniform wall temperature does. Bhattacharyya et al. [8] considered the influence of thermal radiation on micropolar fluid flow over a shrinking sheet and obtained a dual solution to the problem. Yacob et al. [9] studied a micropolar fluid in a steady stagnation-point flow towards a sheet. They observed that the thickness of thermal boundary layer for stretching sheet is lower than for shrinking sheet. In another work, micropolar fluid flow over a shrinking sheet as a stagnation-point flow is studied by Ishak et al. [10]. They used shooting method with two different initial guesses to obtain a dual solution. Miclavcic and Wang [11] presented an exact solution for viscous flow over a shrinking sheet. In addition, Wang [12] studied stagnation flow over a shrinking sheet and observed that the thickness of thermal boundary layer increases by convective heat transfer. Yacob and Ishak [13] showed that there is a dual solution for a micropolar fluid flow over a shrinking sheet, and the values of velocity profile increase for upper branch solution and 
decrease for lower branch solution by augmentation of suction parameter. Nadeem et al. [14] considered a micropolar fluid in a stagnation-point flow over a shrinking sheet. They simplified the governing equations by similarity solutions and solved them by homotopy analysis method. Rosali et al. [15] solved nonsimilar equations by similarity solution and Keller-box method to study the micropolar fluid flow towards a stretching/shrinking sheet, which led to a dual solution for the flow on the shrinking sheet and a unique solution for the stretching sheet. Hossain et al. [16] investigated a viscous fluid passing through a wedge with variable viscosity and thermal conductivity and showed that the decline of variable thermal conductivity increases the local friction coefficient and Nusselt number. El-Kabeir et al. [17] presented an analysis to consider a viscous fluid passing along a moving plate in the presence of Soret and Dufour effects with variable viscosity and thermal conductivity. Ishak [18] presented a numerical analysis to study the velocity and temperature distributions in a micropolar fluid flow over a stretching sheet with thermal radiation effects, and expressed that the thermal boundary layer thickness is enhanced by addition of radiation parameter and reduction of material parameter. Nazar et al. [19] presented an analysis for a mixed convection micropolar fluid flow towards a heated/cooled horizontal circular cylinder by Keller-box method, and considered the separation point and other flow characteristics. Mahmoud and Waheed [20] studied the micropolar fluid film over a moving porous plate. They concluded that the increase of radiation parameter declines Nusselt number. Hussain et al. [21] reported the radiation effects on a micropolar fluid flow towards a permeable and isotherm sheet by homotopy analysis method and showed that temperature values are enhanced by diminution of radiation and material parameter, and suction effects cause the lower velocity values. Das [22] considered MHD micropolar fluid flow in the presence of radiation heat flux, thermophoresis and chemical reaction. They showed that both thermophoretic parameter and chemical reaction rate parameter increase the temperature values. Rashidi et al. [23] described a steady, two-dimensional and incompressible micropolar fluid flow over a permeable sheet and presented an analytical solution by homotopy analysis method to consider distributions of velocity, angular velocity and temperature by variations of contributing parameters. Rahman et al. [24] analyzed micropolar fluid over an inclined porous plate, and reported that heat generation leads to larger Nusselt number. Taklifi and Aghanajafi [25] analyzed the effect of MHD on steady two-dimensional laminar mixed flow over a vertical porous surface. They solved the governing equations by Keller-box method and reported that the increase of magnetic field parameter or porous medium parameter raises the dimensionless velocity.

Here, the flow is supposed laminar, two-dimensional, steady and incompressible, and the body forces are neglected. The applied magnetic field is considered uniform along the sheet and the thermal condition of the sheet is supposed isothermal. Furthermore, the sheet stretches linearly and it is assumed permeable. What distinguishes the problem in this research from other studies is the simultanious presence of thermal radiation, magnetic field and micropolar fluid flow with variable viscosity and thermal conductivity over a permeable stretching sheet, and discussion about their influences on the variations of velocity and temperature profiles by physical reasons.

This study may provide the integral background to the improvement of efficiency and heat transfer rate from a porous insulation, applied in high-temprature furnaces under different conditions. The importance of magnetic field and thermal radiation, resulting from such a high temperature in many complex industrial uses, and the need for more efficient porous insulation necessitate the studying of new fluids and methods to improve the thermal function of insulation, which might be using micropolar fluid motion due to a stretching sheet.

\section{Method of solution}

The problem is a micropolar fluid flow due to a stretching sheet. In the physical infinity, the fluid is stationary and the stretching sheet leads to the fluid motion. The $x$-axis is chosen along the sheet, and the yaxis is taken normal to it (Fig. 1).

Supposing that microinertia is assumed fixed, the governing equations using theory of micropolar fluid [26] and boundary layer approximation are written as follows:

$$
\begin{aligned}
& \frac{\partial u}{\partial x}+\frac{\partial v}{\partial y}=0 \\
& u \frac{\partial u}{\partial x}+v \frac{\partial u}{\partial y}=\frac{1}{\rho} \frac{\partial}{\partial y}\left((\mu+\mathrm{S}) \frac{\partial u}{\partial y}\right)+\frac{S}{\rho} \frac{\partial N}{\partial y}-\sigma B^{2} \frac{u}{\rho} \\
& u \frac{\partial N}{\partial x}+v \frac{\partial N}{\partial y}=\frac{1}{\rho} \frac{\partial}{\partial y}\left(\left(\mu+\frac{S}{2}\right) \frac{\partial N}{\partial y}\right)-\frac{S}{\rho j}\left(2 N+\frac{\partial u}{\partial y}\right) \\
& u \frac{\partial T}{\partial x}+v \frac{\partial T}{\partial y}=\frac{1}{\rho C_{p}} \frac{\partial}{\partial y}\left(k \frac{\partial T}{\partial y}\right)-\frac{1}{\rho C_{p}} \frac{\partial q_{r}}{\partial y}+\sigma \frac{B^{2} u^{2}}{\rho C_{p}}
\end{aligned}
$$

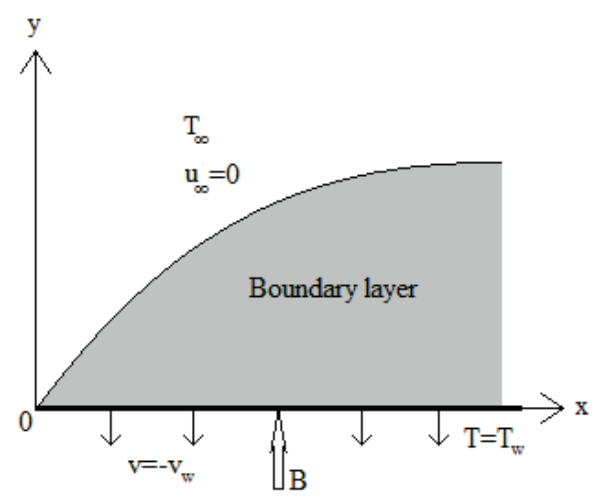

Figure 1 Physical schematic of the problem

In above equations $u, v, N$ and $T$ are horizental velocity, vertical velocity, angular velocity and temperature, also $\rho, \mu, S, j, k, C_{\mathrm{p}}, \sigma, B$ represent density, viscosity, vortex viscosity, micro-inertia, thermal conductivity coefficient, specific heat capacity, electrical conductivity and magnetic field intensity, respectively.

In order, Eqs. (1) $\div$ (4) describe the conservation of mass, momentum, angular momentum and energy for this problem. Given the large optical thickness for a diffusion 
medium, the Rosseland approximation could be applied to define radiation heat flux [27]:

$q_{r}=-\left(\frac{4 \xi}{3 \kappa}\right) \partial T^{4} / \partial y$

In Eq. (5) $\xi$ and $\kappa$ are known as Stefan-Boltzmann constant and absorption coefficient. The expansion of $T^{4}$ in Taylor series would be written as follows:

$$
\begin{aligned}
& T^{4}=T_{\infty}^{4}+4 T_{\infty}^{3}\left(T-T_{\infty}\right)+6 T_{\infty}^{2}\left(T-T_{\infty}\right)^{2}+\ldots \\
& \approx-3 T_{\infty}^{4}+4 T_{\infty}^{3} T
\end{aligned}
$$

So, the energy equation is transformed into:

$$
\begin{aligned}
& u \frac{\partial T}{\partial x}+v \frac{\partial T}{\partial y}=\frac{1}{\rho C_{p}} \frac{\partial}{\partial y}\left(k \frac{\partial T}{\partial y}\right)+\frac{16 \xi T_{\infty}^{3}}{3 \kappa \rho C_{p}} \frac{\partial^{2} T}{\partial y^{2}} \\
& +\sigma \frac{B^{2} u^{2}}{\rho C_{p}}
\end{aligned}
$$

According to the governing assumptions, the sheet is isothermal and stretching, defined by a linear function with constant c. Moreover, the effect of suction would be considered by constant velocity of fluid penetration into the porous sheet, so the boundary conditions at the wall $(y=0)$ are written by:

$$
\begin{aligned}
& T=T_{w} \\
& u=c x, c>0 \\
& v=-v_{w}, v_{w}>0 \\
& N=-m \frac{\partial u}{\partial y}
\end{aligned}
$$

With respect to the theory of micropolar fluid and boundary layer approximation, the angular velocity is defined as Eq. (8-d). In this boundary condition, constant $\mathrm{m}$ is microrotation parameter which could be a value between $0 \div 1$. When $m=0$; then $N=0$, which represents concentrated particle flow, in which the micro-elements are close to the wall and cannot rotate [28], this status is known by strong focus on micro-elements [29]; in addition, $m=0,5$ represents vanishing the asymmetric part of stress tensor and it means weak focus on microelements [30]. When $m=1$, turbulence boundary layer can be modeled [31]. This study solved the governing equations and extracted the results for $m=0,5$.

Also, the boundary conditions in far from the wall $(y \rightarrow \infty)$ are as follows:

$$
\begin{aligned}
& T \rightarrow T_{\infty} \\
& u \rightarrow 0 \\
& N \rightarrow 0
\end{aligned}
$$

Kays [32] observed that the thermal conductivity coefficient has a linear relationship with temperature in an extensive range of temperature. The present study applied such a linear relationship for thermal conductivity coefficient [4]:

$k=k_{\infty}\left(1+\varepsilon \frac{T-T_{\infty}}{T_{w}-T_{\infty}}\right), \varepsilon=\frac{k_{w}-k_{\infty}}{k_{\infty}}$

In Eq. (10), $\varepsilon$ is variable thermal conductivity parameter. Despite the existence of several temperaturedependent relationships to define dynamic viscosity, such as Reynolds viscosity model [33] or Vogel's viscosity model [34], the following relationship, which is more suitable for a wide range of temperature, is used [2]:

$\frac{1}{\mu}=\frac{1}{\mu_{\infty}}\left[1+\gamma\left(\mathrm{T}-\mathrm{T}_{\infty}\right)\right]$

In Eq. (11), $\gamma$ is a thermal propertiy of the fluid, which is a positive value for liquids and a negative value for gases, provided that the wall temperature is higher than the fluid's [3]. Since the flow is supposed twodimensional and incompressible, stream function could be used for similarity solution to transform PDEs to ODEs by using the following non-dimensional variables [18]:

$$
\begin{aligned}
& u=\partial \psi / \partial y \\
& v=-\partial \psi / \partial x \\
& \eta=\left(c / v_{\infty}\right)^{1 / 2} y \\
& \psi=\left(c v_{\infty}\right)^{\frac{1}{2}} x f(\eta) \\
& N=c x\left(c / v_{\infty}\right)^{1 / 2} h(\eta) \\
& T=T_{\infty}+\left(T_{w}-T_{\infty}\right) \theta(\eta)
\end{aligned}
$$

In Eq. (12) $\psi, v$ are stream function and kinematic viscosity, and $f, h, \theta, \eta$ are dimensionless stream function, angular velocity, temperature and similarity variable, respectively.

By substituting above similarity transformation, Eq. (10) and Eq. (11) are transformed into:

$$
\begin{aligned}
& k=k_{\infty}(1+\varepsilon \theta(\eta)) \\
& \mu=\mu_{\infty}\left(\frac{\theta_{r}}{\theta_{r}-\theta}\right)
\end{aligned}
$$

In Eq. (14), $\theta_{r}$ is variable viscosity parameter which is defined as follows:

$$
\theta_{r}=-\frac{1}{\gamma\left(T_{w}-T_{\infty}\right)}
$$

The governing equations are transformed into nonlinear ODEs by substituting Eqs. (12) $\div(14)$, as follows:

$$
\begin{aligned}
& {\left[\frac{\theta_{r}}{\theta_{r}-\theta(\eta)}+\Delta\right] f^{\prime \prime \prime}(\eta)+\frac{\theta_{r}}{\left(\theta_{r}-\theta(\eta)\right)^{2}} f^{\prime \prime}(\eta) \theta^{\prime}(\eta)} \\
& +f(\eta) f^{\prime \prime}(\eta)-f^{\prime 2}(\eta)+\Delta h^{\prime}(\eta)-(H a)^{2} f^{\prime}(\eta)=0
\end{aligned}
$$


$\left[\frac{\theta_{r}}{\theta_{r}-\theta(\eta)}+\frac{\Delta}{2}\right] h^{\prime \prime}(\eta)+\frac{\theta_{r}}{\left(\theta_{r}-\theta(\eta)\right)^{2}} h^{\prime}(\eta) \theta^{\prime}(\eta)$

$+f(\eta) h^{\prime}(\eta)-f^{\prime}(\eta) h(\eta)-\Delta\left[2 h(\eta)+f^{\prime \prime}(\eta)\right]=0$

$((1+\varepsilon \theta(\eta))+R a) \theta^{\prime \prime}(\eta)+\varepsilon \theta^{\prime 2}(\eta)+P r_{\infty} f(\eta) \theta^{\prime}(\eta)$

$+\operatorname{Pr}_{\infty}(H a)^{2} E c f^{\prime 2}(\eta)=0$

The boundary conditions are transformed, as well:

$$
\begin{aligned}
& \theta(\eta)=1 \\
& f^{\prime}(\eta)=1 \\
& f(\eta)=M \quad \text { at } \eta=0 \\
& h(\eta)=-m f^{\prime \prime}(\eta)
\end{aligned}
$$

And

$$
\theta(\eta) \rightarrow 0
$$

$f^{\prime}(\eta) \rightarrow 0$

at $\eta \rightarrow \infty$

$h(\eta) \rightarrow 0$

In all equations, the subscripts $\mathrm{w}$ and $\infty$ show the quantities on the wall and far from the surface. With regard to the definition of dimensionless angular velocity mentioned in Eq. (19), distribution of dimensionless angular velocity is completely influenced by gradient of dimensionless velocity. Therefore, the increase of absolute values of velocity gradient causes more values of angular velocity and vice versa. In the above equations, dimensionless parameters are as follows:

$$
\begin{aligned}
& P r_{\infty}=\frac{\mu_{\infty} C_{p}}{k_{\infty}}, E c=\frac{c^{2} x^{2}}{C_{p}\left(T_{w}-T_{\infty}\right)}, \Delta=\frac{S}{\mu_{\infty}}, R a=\frac{16 \xi T_{\infty}^{3}}{3 k_{\infty} \kappa}, \\
& H a=B \sqrt{\frac{\sigma}{\rho c}}, \mathrm{M}=\frac{v_{w}}{\left(c v_{\infty}\right)^{1 / 2}}
\end{aligned}
$$

These dimensionless parameters are named as Prandtl number, Eckert number, material parameter, radiation parameter, Hartmann number and suction parameter, respectively.

Here, shooting method served to transform the boundary value problem into initial value problem. Finally, they are solved by fourth-order Runge-Kutta method in symbolic software Mathematica.

\section{Results and discussion}

In this paper the numerical results are obtained for every desired parameter, while the values of other dimensionless parameters are considered fixed and supposed unit, other than the variable viscosity parameter which is assumed minus two as the representative of

\begin{tabular}{|c|c|c|c|c|c|c|c|}
\hline$R a$ & $\Delta$ & $P r$ & Grubka and Bobba [35] & Ali [36] & Chen [37] & Ishak [18] & Present \\
\hline 0 & 0 & 0,72 & 0,4631 & 0,4617 & 0,46315 & 0,4631 & 0,463592 \\
\hline 0 & 0 & 1 & 0,5820 & 0,5801 & 0,58199 & 0,5820 & 0,582011 \\
\hline 0 & 0 & 3 & 1,1652 & 1,1599 & 1,16523 & 1,1652 & 1,165240 \\
\hline 0 & 0 & 10 & 2,3080 & 2,2960 & 2,30796 & 2,3080 & 2,308000 \\
\hline 1 & 0 & 1 & & & & 0,3547 & 0,357240 \\
\hline 1 & 1 & 1 & & & & 0,3893 & 0,391301 \\
\hline
\end{tabular}
liquid fluid.

The initial gradient conditions achieved by shooting method play a significant role in ultimate solution. Therefore, to validate the results, the values of $-\theta^{\prime}(0)$ are compared with $[35,36,37,18]$ and brought in Tab. 1 . The very close answers certify the present results.

Table 1 Values of $-\theta^{\prime}(0)$ for various values of $R a, \Delta$ and $\operatorname{Pr}$ when $H a=0, M=0, m=0,5, \varepsilon=0$ and $\theta_{r} \rightarrow \infty$

A numerical analysis has been done to study the influences of different parameters on a micropolar fluid flow with temperature-dependent properties and heat transfer from a stretching sheet. The effects of various parameters on velocity profiles and temperature profiles are shown graphically in Fig. $2 \div 15$.

Fig. 2 and Fig. 3, show the effect of variable thermal conductivity parameter on temperature profile and velocity profile, respectively. According to Eq. (13), the increase of variable thermal conductivity parameter leads to more thermal conductivity coefficient, which results in further thermal diffusion through the fluid. Hence, the values of dimensionless temperature in the thermal boundary layer increase and temperature gradient on the wall and heat transfer rate from the sheet dwindle. Based on Eq. (14), higher values of temperature result in lower viscosity which accelerates the fluid motion.

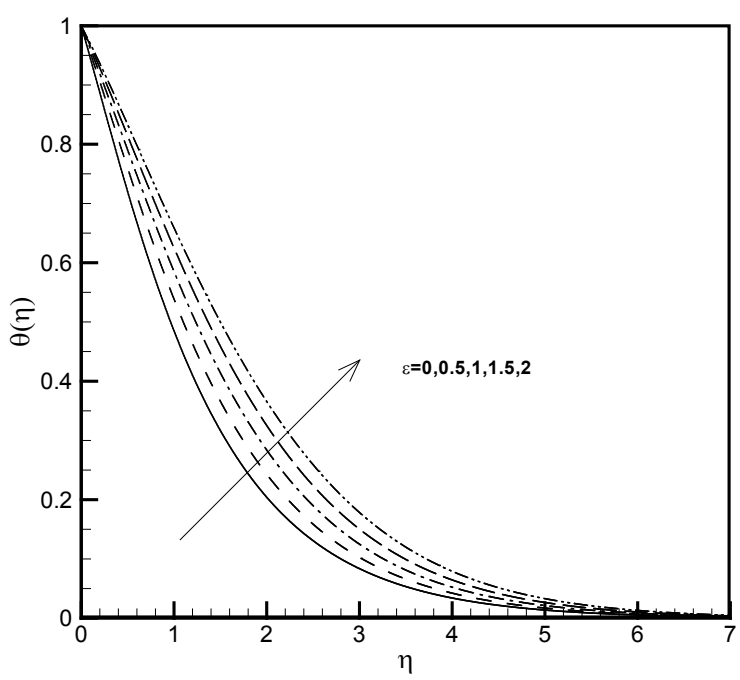

Figure 2 Temperature profiles for different values of $\varepsilon$

Fig. 4 and Fig. 5 represent the effects of presence and increase of magnetic field intensity on velocity and temperature profiles, respectively. Applying magnetic 
field in an electrically conducting fluid flow creates a drag force called Lorentz force, which reduces the fluid velocity. Consequently, the increase of Hartmann number reduces the rate of transport, and the thickness of the momentum boundary layer decreases. On the other hand, the resistance against the flow, created by Lorentz force, causes more heat transport rate through the fluid known as Joule heating. Therefore, the values of temperature in the boundary layer increase and the absolute temperature gradients at the surface and heat transfer from the sheet decline.

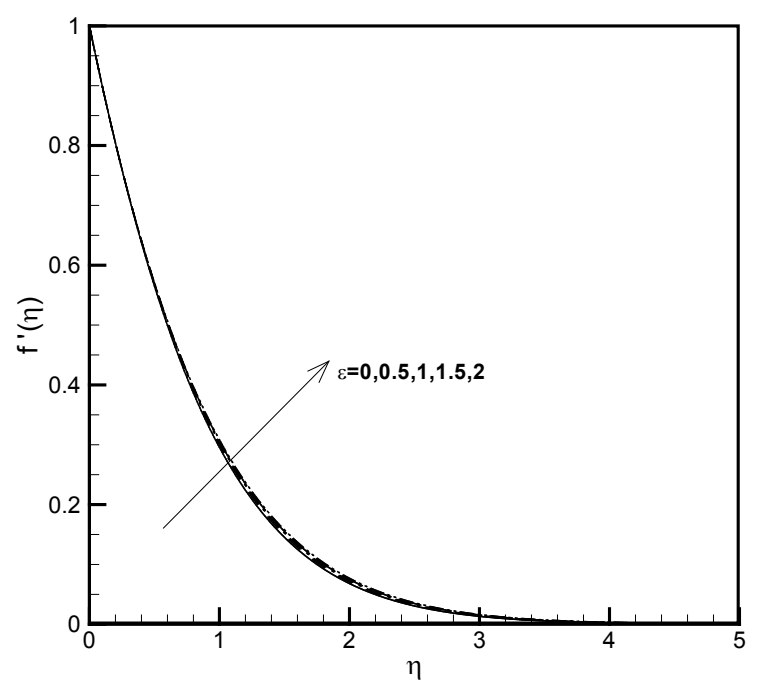

Figure 3 Velocity profiles for different values of $\varepsilon$

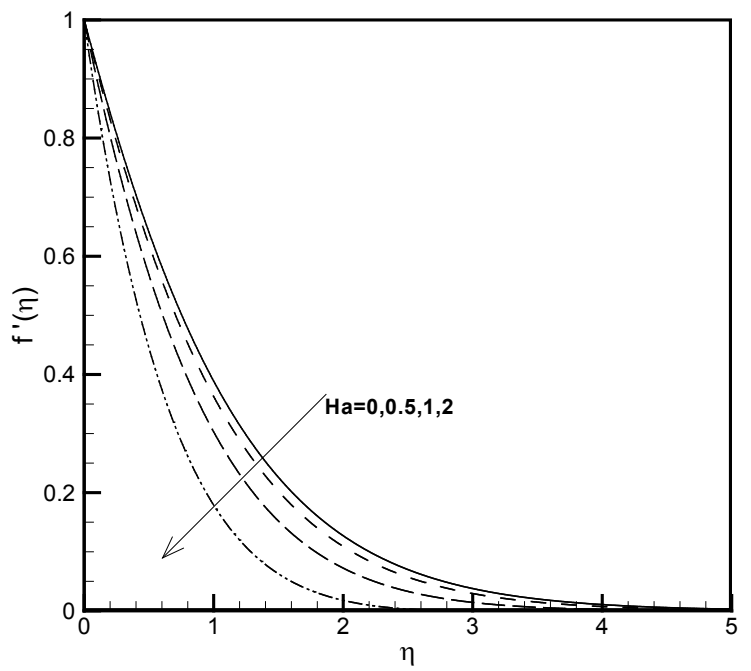

Figure 4 Velocity profiles for different values of $\mathrm{Ha}$

Fig. 6 and Fig. 7, show the effects of the material parameter as an important characteristic of micropolar fluid, on velocity and temperature profiles, respectively. It is obvious that the increase of material parameter thickens the momentum boundary layer and reduces the values of temperature profile, so the absolute values of temperature gradient are lowered and heat transfer from the sheet is enhanced.

Fig. 8 and Fig. 9 depict the effects of Prandtl number on velocity and temperature profiles. Prandtl number is the ratio of viscous forces to thermal diffusion, so the addition of $\mathrm{Pr}$ number implies more resistant force in fluid motion and reduction of velocity values. Also, less thermal diffusion leads to the lower energy transport through the fluid and more absolute values of temperature gradient on the surface, which causes the enhancement of heat transfer rate from the sheet.

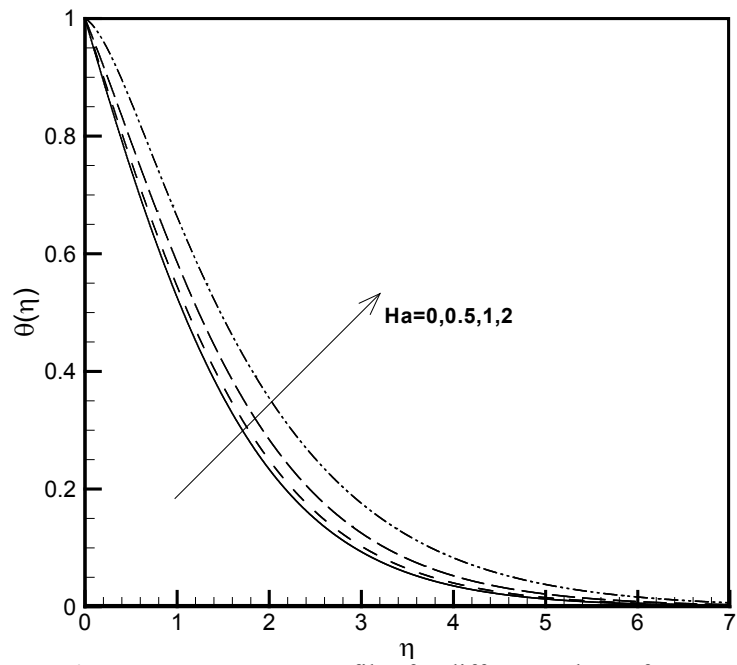

Figure 5 Temperature profiles for different values of $\mathrm{Ha}$

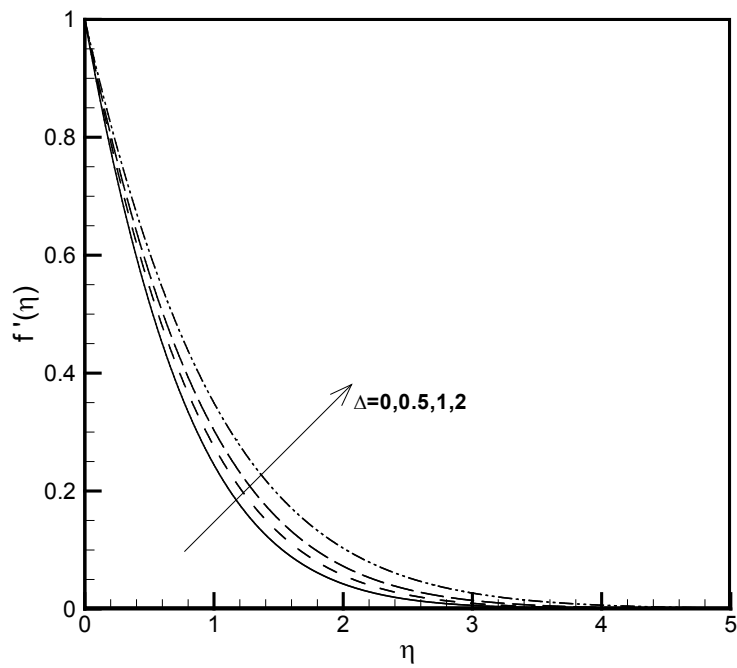

Figure 6 Velocity profiles for different values of $\Delta$

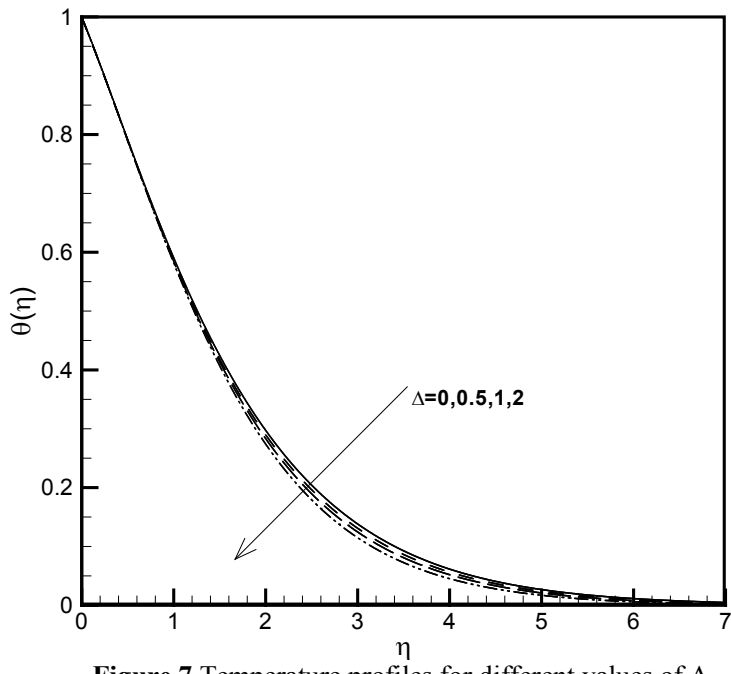

Figure 7 Temperature profiles for different values of $\Delta$

Fig. 10 shows the effects of radiation heat transfer on temperature profiles by variations of thermal radiation parameter. The presence and increase of thermal radiation parameter augment the temperature values in the thermal 
boundary layer. According to the definition of radiation parameter, increase of $\mathrm{Ra}$ implies decrease of absorption coefficient; then more radiation heat flux defined by Eq. (5), so the rate of energy transport to the fluid and the values of temperature distribution increase. Finally, according to Eq. (14), more temperature values result in lower viscosity and higher velocity values (Fig. 11).

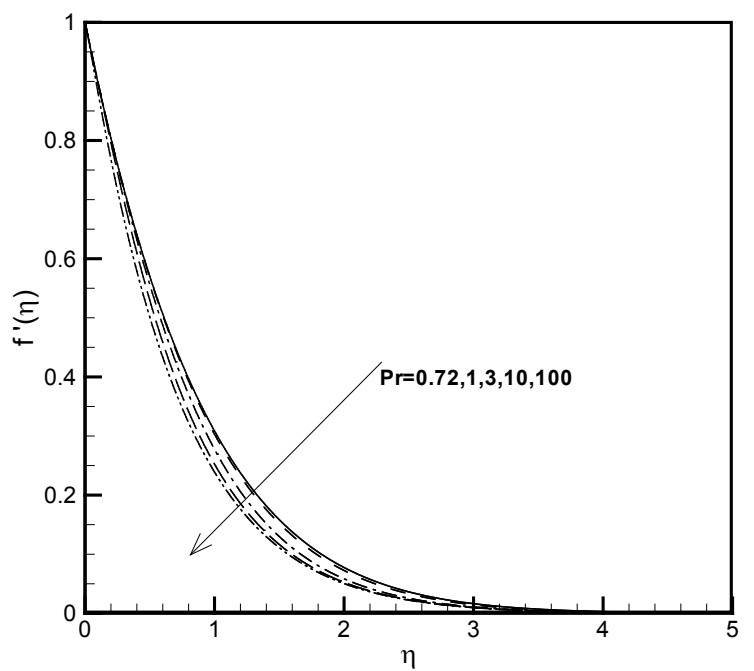

Figure 8 Velocity profiles for different values of $\mathrm{Pr}$

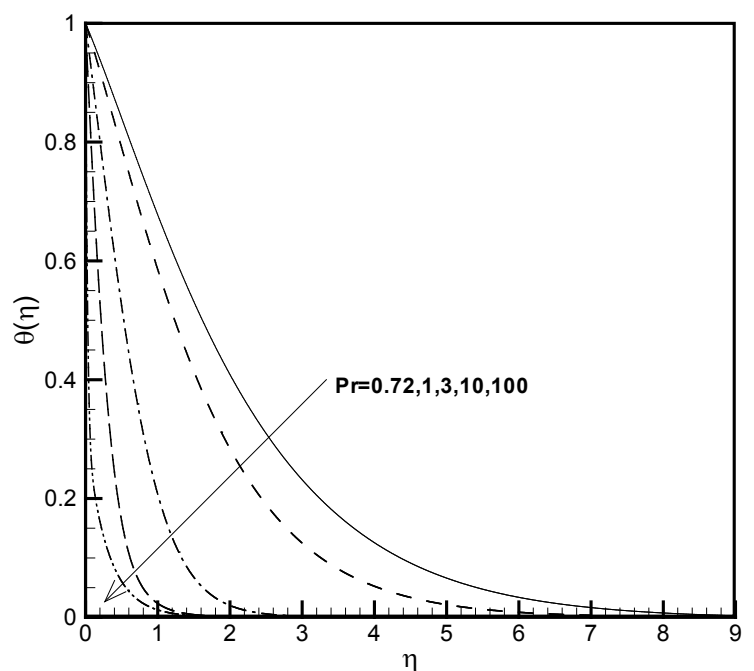

Figure 9 Temperature profiles for different values of $\mathrm{Pr}$

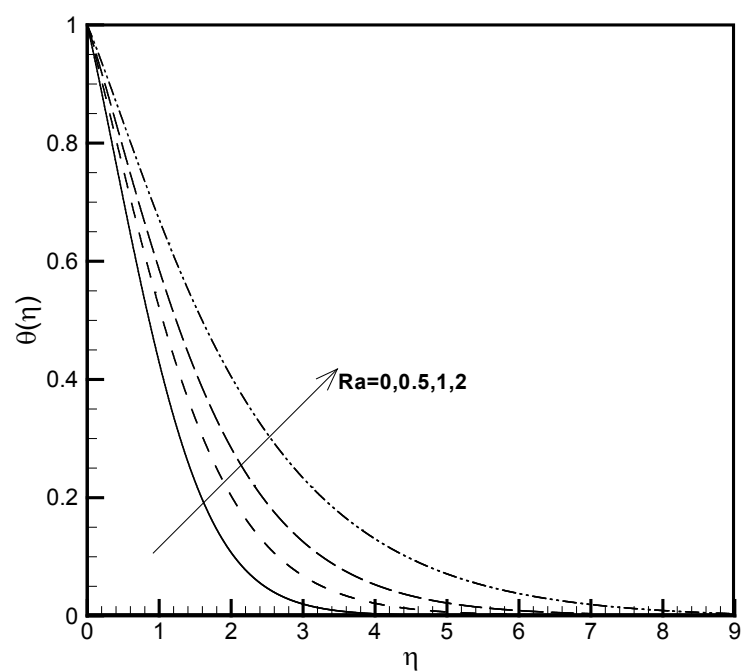

Figure 10 Temperature profiles for different values of $R a$

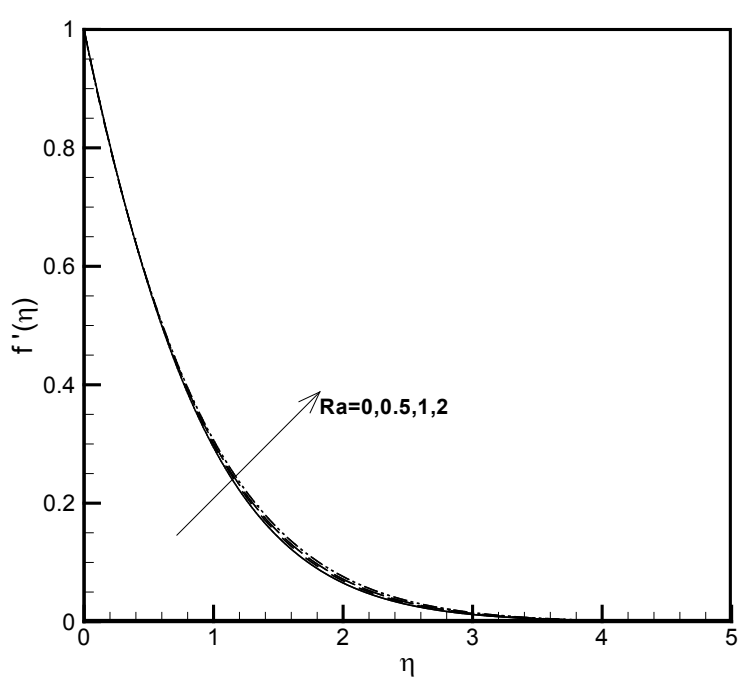

Figure 11 Velocity profiles for different values of $\mathrm{Ra}$

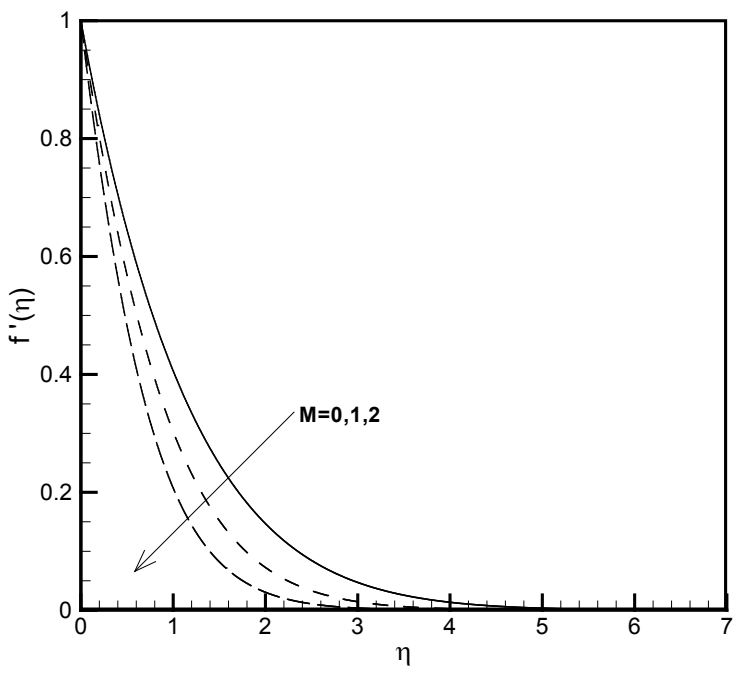

Figure 12 Velocity profiles for different values of $M$

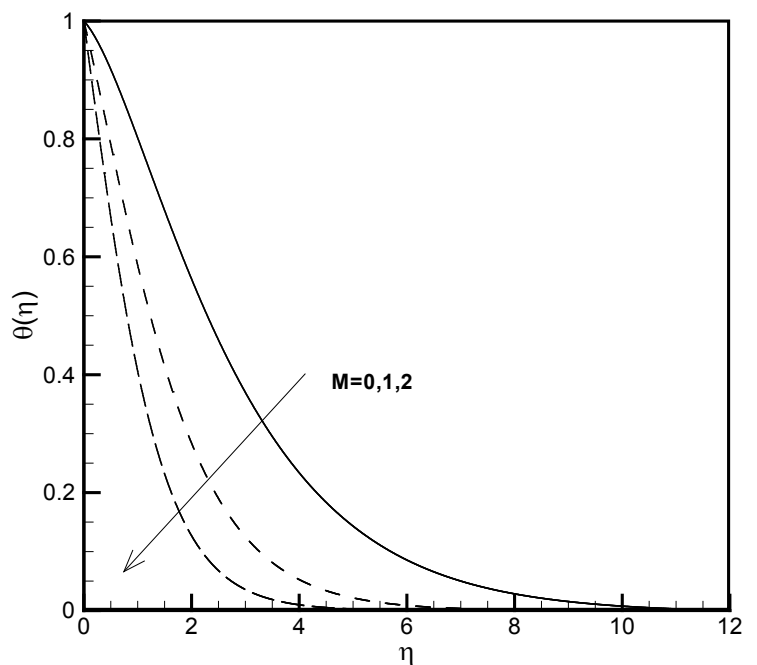

Figure 13 Temperature profiles for different values of $M$

Fig. 12 displays the effect of suction parameter on velocity profiles. Augmentation of fluid penetration velocity into the sheet by enhancement of suction parameter, reduces the total momentum in the flow direction, and lowers dimensionless velocity values. On the other hand, Fig. 13 shows that more fluid penetration into the sheet causes thinner thermal boundary layer and 
higher heat transfer rate due to the faster replacement of heated fluid with the cooler fluid.

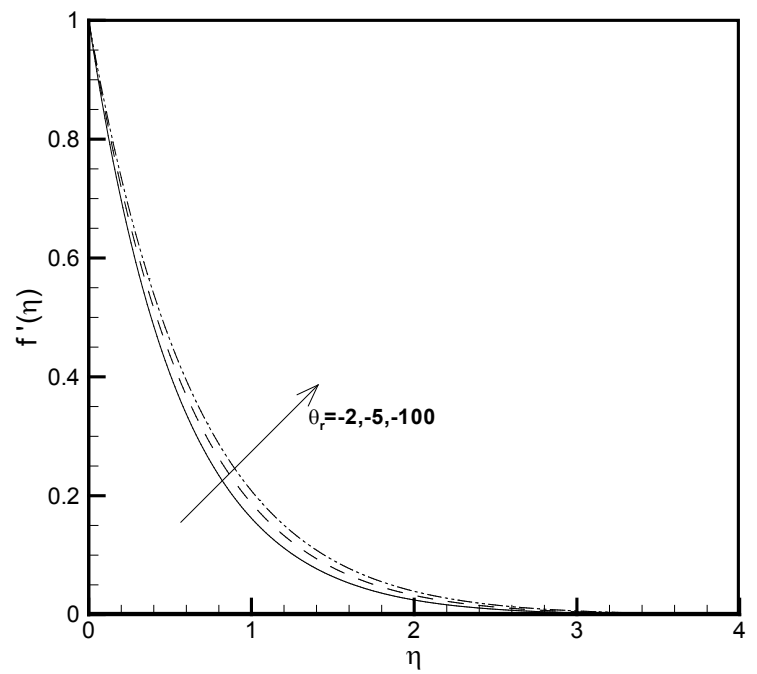

Figure 14 Velocity profiles for different values of $\theta_{\mathrm{r}}$

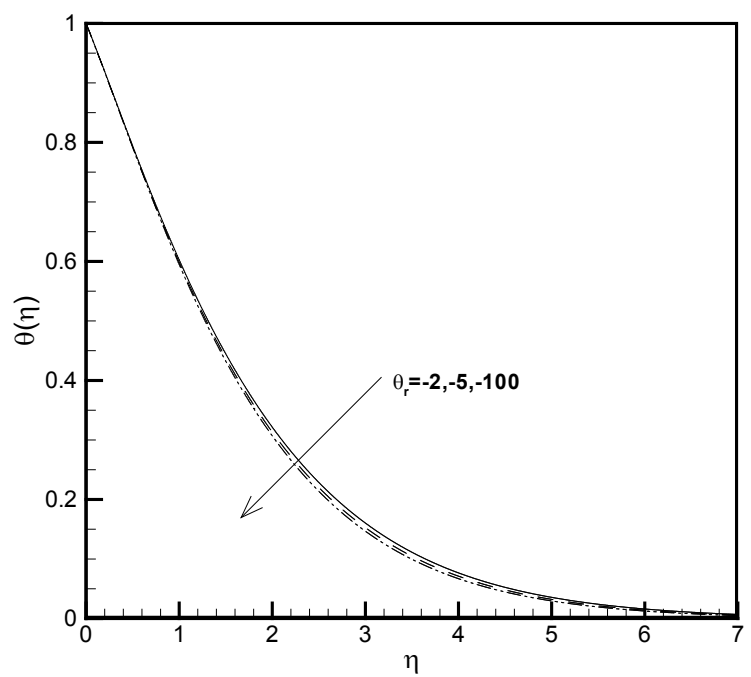

Figure 15 Temperature profiles for different values of $\theta_{\mathrm{r}}$

Fig. 14 and Fig. 15 display the effects of various values of variable viscosity parameter on the velocity and temperature profiles, respectively. The augmentation of absolute values of $\theta_{\mathrm{r}}$ results in increase of dynamic viscosity which leads to decrease of velocity values in momentum boundary layer. Also, the reduction of fluid velocity slows down the replacement of heated fluid with cooler fluid, so temperature values in thermal boundary layer increase and heat transfer rate from the sheet declines.

\section{Conclusion}

This research investigated the characteristics of micropolar fluid flow over a stretching sheet and heat transfer from the sheet to the fluid; also, the effects of the presence and intensity of radiation, magnetic field, porous sheet and Prandtl number are considered. To obtain more exact solution, viscosity and thermal conductivity are supposed temperature-dependent, and the influences of variable viscosity parameter and variable thermal conductivity parameter are studied. The results show that the presence of radiation and magnetic field and the increase of variable viscosity and variable thermal conductivity parameters reduce heat transfer rate while the increase of suction parameter and Prandtl number enhance the cooling rate. Besides, the results show that the increase of variable thermal conductivity, radiation and material parameters thicken the velocity boundary layer though other parameters have inverse effects on its thickness.

\section{$5 \quad$ References}

[1] Eringen, A. C. Simple microfluids. // International Journal of Engineering Science. 2, 2(1964), pp.205-217. DOI: 10.1016/0020-7225(64)90005-9

[2] Prasad, K. V.; Pal, D.; Umesh, V.; Rao, N. S. The effect of variable viscosity on MHD viscoelastic fluid flow and heat transfer over a stretching sheet. // Communications in Nonlinear Science and Numerical Simulation. 15, 2(2010), pp. 331-344. DOI: 10.1016/j.cnsns.2009.04.003

[3] Prasad, K. V.; Vajravelu, K.; Datti, P. S. The effects of variable fluid properties on the hydro-magnetic flow and heat transfer over a non-linearly stretching sheet. // International Journal of Thermal Sciences. 49, 3(2010), pp. 603-610. DOI: 10.1016/j.ijthermalsci.2009.08.005

[4] Chiam, T. C. Heat transfer with variable conductivity in a stagnation-point flow towards a stretching sheet. // International Communications in Heat and Mass Transfer. 23, 2(1996), pp. 239-248. DOI: 10.1016/0735-1933(96)00009-7

[5] Odda, S. N.; Farhan, A. M. Chebyshev finite difference method for the effects of variable viscosity and variable thermal conductivity on heat transfer to a micro-polar fluid from a non-isothermal stretching sheet with suction and blowing. // Chaos, Solitons \& Fractals. 30, 4(2006), pp. 851-858. DOI: 10.1016/j.chaos.2005.08.111

[6] Mahmoud, M. A. A. Thermal radiation effects on MHD flow of a micropolar fluid over a stretching surface with variable thermal conductivity. // Physica A. 375, 2(2007), pp. 401-410. DOI: 10.1016/j.physa.2006.09.010

[7] Rahman, M. M.; Rahman, M. A.; Samad, M. A.; Alam, M. S. Heat Transfer in a Micropolar Fluid along a non-linear stretching sheet with a temperature-dependent viscosity and variable surface temperature. // International Journal of Thermophysics. $30,5(2009)$, pp. 1649-1670. DOI: 10.1007/s10765-009-0656-5

[8] Bhattacharyya, K.; Mukhopadhyay, S.; Layek G. C.; Pop, I. Effects of thermal radiation on micropolar fluid flow and heat transfer over a porous shrinking sheet. // International Journal of Heat and Mass Transfer. 55, 11-12(2012), pp. 2945-2952. DOI: 10.1016/j.ijheatmasstransfer.2012.01.051

[9] Yacob, N. A.; Ishak, A.; Pop I. Melting heat transfer in boundary layer stagnation-point flow towards a stretching/shrinking sheet in a micropolar fluid. // Computers \& Fluids. 47, 1(2011), pp. 16-21. DOI: 10.1016/j.compfluid.2011.01.040

[10] Ishak, A.; Lok, Y. Y.; Pop I. Stagnation-Point flow over a shrinking sheet in a micropolar Fluid. // Chemical Engineering Communications. 197, 11(2010), pp. 14171427. DOI: $10.1080 / 00986441003626169$

[11] Miklavcic, M.; Wang, C. Y. Viscous flow due to a shrinking sheet. // Quarterly of Applied Mathematics. 64, (2006), pp. 283-290. DOI: 10.1090/S0033-569X-06-01002-5

[12] Wang, C. Y. Stagnation flow towards a shrinking sheet. // International Journal of Non-Linear Mechanics. 43, 5(2008), pp. 377-382. DOI: 10.1016/j.jijnonlinmec.2007.12.021

[13] Yacob, N. A.; Ishak, A. Micropolar fluid flow over a shrinking sheet. // Meccanica. 47, 2(2012), pp. 293-299. DOI: 10.1007/s11012-011-9439-8

[14] Nadeem, S.; Abbasbandy, S; Hussain, M. Series solutions of boundary layer flow of a micropolar fluid near the 
stagnation point towards a shrinking sheet. // Zeitschrift für Naturforschung. 64, 9-10(2009), pp. 575-582. DOl: 10.1515/zna-2009-9-1006

[15] Rosali, H.; Ishak, A.; Pop, I. Micropolar fluid flow towards a stretching/shrinking sheet in a porous medium with suction. // International Communications in Heat and Mass Transfer. $\quad 39, \quad 6(2012)$, pp. 826-829. DOl: 10.1016/j.icheatmasstransfer.2012.04.008

[16] Hossain, M. A.; Munir, M. S.; Rees, D. A. S. Flow of viscous incompressible fluid with temperature dependent viscosity and thermal conductivity past a permeable wedge with uniform surface heat flux. // International Journal of Thermal Sciences. 39, 6(2000), pp. 635-644. DOI: 10.1016/S1290-0729(00)00227-1

[17] El-Kabeir, S. M. M.; Modather, M; Rees, D. A. S.; Rashad, A. M. Soret and Dufour effects on heat and mass transfer from a continuously moving plate embedded in porous media with temperature dependent viscosity and thermal conductivity. // Journal of modern methods in numerical mathaematics. 4, 2(2013), pp. 10-22. DOl: 10.20454/jmmnm.2013.562

[18] Ishak, I. Thermal boundary layer flow over a stretching sheet in a micropolar fluid with radiation effect. // Meccanica. 45, 3(2010), pp. 367-373. DOI: 10.1007/s11012009-9257-4

[19] Nazar, R.; Amin, N.; Pop, I. Mixed convection boundarylayer flow from a horizontal circular cylinder in micropolar fluids: case of constant wall temperature. // International Journal of Numerical Methods for Heat \& Fluid Flow. 13, 1(2003), pp. 86-109. DOI: 10.1108/09615530310456778

[20] Mahmoud, M. A. A.; Waheed, S. E. Variable fluid properties and thermal radiation effects on flow and heat transfer in micropolar fluid film past moving permeable infinite flat plate with slip velocity. // Applied Mathematics and Mechanics. 33, 5(2012), pp. 663-678. DOl: 10.1007/s10483-012-1578-x

[21] Hussain, M.; Ashraf, M.; Nadeem, S.; Khan, M. Radiation effects on the thermal boundary layer flow of a micropolar fluid towards a permeable stretching sheet. // Journal of the Franklin Institute. 350, 1(2013), pp. 194-210. DOI: 10.1016/j.jfranklin.2012.07.005

[22] Das, K. Influence of thermophoresis and chemical reaction on MHD micropolar fluid flow with variable fluid properties. // International Journal of Heat and Mass Transfer. 55, 23-24(2012), pp. 7166-7174. DOl: 10.1016/j.jijheatmasstransfer.2012.07.033

[23] Rashidi, M. M.; Mohimanian pour, S. A.; Abbasbandy, S. Analytic approximate solutions for heat transfer of a micropolar fluid through a porous medium with radiation. // Communications in Nonlinear Science and Numerical Simulation. 16, 4(2011), pp. 1874-1889. DOl: 10.1016/j.cnsns.2010.08.016

[24] Rahman, M. M.; Aziz, A.; Al-Lawatia, M. A. Heat transfer in micropolar fluid along an inclined permeable plate with variable fluid properties. // International Journal of Thermal Sciences. 49, 6(2010), pp. 993-1002. DOI: 10.1016/j.jithermalsci.2010.01.002

[25] Taklifi, A.; Aghanajafi, C. MHD non-Darcian flow through a non-isothermal vertical surface embedded in a porous medium with radiation. // Meccanica. 47, 4(2012), pp. 929937. DOI: $10.1007 / \mathrm{s} 11012-011-9484-3$

[26] Eringen, A. C. Theory of micropolar fluids. // Journal of Mathematics and Mechanics. 16, (1965), pp. 1-18.

[27] Brewster, M. Q. Thermal Radiative Transfer and properties. John Wiley and Sons, 1992.

[28] Jena, S. K.; Mathur, M. N. Similarity solutions for laminar free convection flow of a thermomicropolar fluid past a non-isothermal vertical flat plate. // International Journal of Engineering Science. 19, 11(1981), pp. 1431-1439. DOI: $10.1016 / 0020-7225(81) 90040-9$
[29] Guram, G. S.; Smith, A. C. Stagnation flow of micropolar fluids with strong and weak interactions. // Computers \& Mathematics with Applications.6, 2(1980), pp. 213-233. DOI: 10.1016/0898-1221(80)90030-9

[30] Ahmadi, G. Self-similar solution of incompressible micropolar boundary layer flow over a semi-infinite plate. // International Journal of Engineering Science. 14, 7(1976), pp. 639-646. DOI: 10.1016/0020-7225(76)90006-9

[31] Peddieson, J. An application of the micropolar fluid model to the calculation of turbulent shear flow. // International Journal of Engineering Science. 10, 1(1972), pp. 23-32. DOI: 10.1016/0020-7225(72)90072-9

[32] Kays, W. M. Convective heat and mass transfer. McGrawHill, 1966.

[33] Knezevic, D.; Savic, V. Mathematical modeling of changing of dynamical viscosity, as a function of temperature and pressure, of mineral oils for hydraulic systems. // Facta Universitatis (Series: Mechanical Engineering). 4, 1(2006), 99.27-34.

[34] Yurusoy, M.; Pakdemirli, M. Approximate analytical solutions for the flow of a third-grade fluid in pipe. // International Journal of Non-Linear Mechanics. 37, 2(2002), pp. 187-95. DOI: 10.1016/S0020-7462(00)00105-0

[35] Grubka, L. J.; Bobba, K.M. Heat transfer characteristics of a continuous, stretching surface with variable temperature. // ASME Journal of Heat Transfer. 107, 1(1985), pp. 248250. DOI: $10.1115 / 1.3247387$

[36] Ali, M. E. Heat transfer characteristics of a continuous stretching surface. // Heat and Mass Transfer. 29, 4(1994), pp. 227-234. DOI: 10.1007/bf01539754

[37] Chen, C. H. Laminar mixed convection adjacent to vertical, continuously stretching sheets. // Heat and Mass Transfer. 33, 5(1998), pp. 471-476. DOI: 10.1007/s002310050217

\section{Authors' addresses}

Reza Keimanesh, M.Sc

K. N. Toosi University of technology, Department of Mechanical Engineering,

No. 15, 17, 19, Pardis Avenue, Vanak square, Tehran, Iran reza_keimanesh@yahoo.com

Cyrus Aghanajafi, Professor

K. N. Toosi University of technology,

Department of Mechanical Engineering

No. 15, 17, 19, Pardis Avenue, Vanak square, Tehran, Iran aghanajafi@kntu.ac.ir 